This item was submitted to Loughborough's Research Repository by the author.

Items in Figshare are protected by copyright, with all rights reserved, unless otherwise indicated.

\title{
The impact of consumer archetypes on online purchase decision-making processes and outcomes: A behavioural process perspective
}

PLEASE CITE THE PUBLISHED VERSION

https://doi.org/10.1016/j.jbusres.2018.05.038

PUBLISHER

(c) Elsevier

VERSION

AM (Accepted Manuscript)

\section{PUBLISHER STATEMENT}

This paper was accepted for publication in the journal Journal of Business Research and the definitive published version is available at https://doi.org/10.1016/j.jbusres.2018.05.038

LICENCE

CC BY-NC-ND 4.0

\section{REPOSITORY RECORD}

Karimi, Sahar, Chris Holland, and K. Nadia Papamichail. 2019. "The Impact of Consumer Archetypes on Online Purchase Decision-making Processes and Outcomes: A Behavioural Process Perspective”. figshare. https://hdl.handle.net/2134/33977. 
The impact of consumer archetypes on online purchase decision-making processes and outcomes: A behavioural process perspective

\begin{abstract}
This study investigates differences in online purchase behaviour between consumer archetypes. It shows how consumers' decision-making styles and product knowledge define distinct archetypal behaviour that shapes online purchase processes and affects decisionrelated outcomes: satisfaction with choice; and satisfaction with process. The first study proposes a new modelling approach that creates an accurate representation of decisionmaking behaviour. Using this method, a clear structure that underlies seemingly chaotic purchase processes is identified. This structure offers an analytical tool capable of capturing behavioural differences between archetypes. The results show that decision-making style and product knowledge affect the structure and complexity of decision-making processes. The second study found that consumers with higher product knowledge are more satisfied with decision-making process and that this relationship is mediated by the duration of decisionmaking. Maximizers are more satisfied with their choice than satisficers, and this relationship is mediated by the number of alternatives that are evaluated.
\end{abstract}

Keywords: consumer decision-making; purchase processes; process modelling; consumer satisfaction; maximization tendency; product knowledge 


\section{Introduction}

The availability of large amounts of online information makes the consumer purchase decision-making process a laborious and frustrating task (Hölscher \& Strube, 2000). To cope with a large number of choices and a large amount of information from a range of different online sources (Hall et al., 2017), consumers adopt suitable decision-making strategies (Payne et al., 1991; Bettman \& Zins, 1979). They continuously adapt their decision strategies and change the trajectory of their decision pathways in response to exposure to new information, resulting in dynamic purchase processes. Consumers construct these processes through a series of behavioural choices. Distinctive decision-making patterns are therefore expected to reflect the characteristics of different consumer segments. Literature on online consumer decision-making suggests that individual characteristics can explain behavioural variations (Darley et al., 2010; Smith \& Rupp, 2003) but there is little empirical evidence to test or support this assertion. Previous research has mainly focused on demographic factors (Ranaweera et al., 2005; Hall et al., 2017) and web experience characteristics (Frambach et al., 2007). However, online consumers "differ in important ways above and beyond demographics and webographics” (Brengman et al., 2005), e.g. motivational drives and personality traits (Morrison et al., 2013), subjective knowledge (Brucks, 1985) and decisionmaking style (Karimi et al., 2015).

Inner capabilities and motivation of decision makers influence their chosen decision strategies (Payne et al., 1993). Consumers’ knowledge of product and maximization tendency, as two individual characteristics that pertain to inner capacity and motivation to locate the best option, shape their purchase decision-making behaviour; which ultimately determines their satisfaction with the choice and process (Heitmann et al., 2007). Based on decision-making style and knowledge, four archetypes of consumers can be identified (satisficer/maximizer and low/high level of knowledge). Previous research has explored the 
effects of consumer archetypes on process-related outcomes. For example, Karimi et al. (2015) showed that knowledge of product and maximization tendency affect process-related outcomes such as number of cycles, duration, number of evaluated alternatives and number of criteria considered. However, they did not address how the decision-making process unfolds, i.e. the underlying mechanics of the process for each consumer archetype. Furthermore, there is little known about the way in which consumer archetypes affect decision-related outcomes such as consumer satisfaction (Kamis et al., 2008). This work addresses these limitations by conducting two studies. The first study expands on Karimi et al. (2015) and presents further analysis of consumer decision-making processes to illustrate the underlying behavioural patterns of the archetypes in a diagrammatic form. The second study was then designed to examine decision-related outcomes using a new sample.

In the first study, the impact of consumer archetypes on purchase process patterns is examined. Video-based data collection techniques recorded an extremely high level of behavioural detail and a process-based, structured modelling approach was used to capture the decision-making processes. This work extends the study by Karimi et al. (2015) by identifying a new concept of decision-making phases, which is a novel framework that encapsulates the dynamic and iterative characteristics of the process. Phases are a higherlevel construct than behavioural roles in traditional models of consumer decision-making behaviour. The framework was applied to four archetypes from which we would expect divergent decision-making behaviour. This was important because it enabled us to test (a) whether the phase model has utility in general, and (b) whether the phase model is effective at identifying differences between consumer segments. A clear structure that underlies highly iterative and chaotic purchase processes was found and distinctive decision-making patterns for each of the four archetypes were identified. This study uncovers granular level decisionmaking behaviour of consumers and illuminates behavioural differences in a holistic but 
highly detailed manner, which has previously been veiled by commonly used experimental methods. It contributes to marketing and decision-making research in two ways. It captures identifiable differences in decision flows for each consumer archetype and introduces a phase model that relates granular level decision-making behaviour to a higher-level structure of inter-linked phase diagrams.

In the second study, our focus moves to decision-related outcomes, which is a crucial but under-researched area (Kamis et al., 2008). Two decision outcome variables that are related to consumers' experiences of the search and buying process are studied: satisfaction with the choice and satisfaction with the decision-making process (McKinney \& Yoon, 2002; Gu et al., 2013). We examine how consumer archetypes explain decision outcomes by influencing online purchase behaviour measured by time duration and number of evaluated alternatives. Two contributions are made. First, we show that decision-making style and knowledge of product affect satisfaction with the choice and satisfaction with the process, respectively. The mediating mechanisms that motivate these relationships are diverse. That is, consumer satisfaction with choice is formed by higher confidence in the choice and is associated with a larger number of alternatives that maximizers evaluate. Satisfaction with the process is reduced by a longer duration of decision-making, which is caused by a low level of product knowledge. Second, further evidence for conceptual differences between the two types of satisfaction is provided.

\section{Theoretical Foundation}

\subsection{Purchase process flow}

Consumer online purchase decision-making is a dynamic process that comprises different stages. The traditional model of purchase decision-making process (Engel et al., 
1968; Howard \& Jagdish, 1969) includes five stages: problem recognition; information search; evaluation of alternatives; purchase decision; and post-purchase behaviour (Figure 1).

Insert Figure 1 around here

This model is the most commonly used framework of consumer purchase behaviour and has been widely used in consumer research. The model's individual elements are treated as discrete stages, and customers move from one stage to the next, eventually making a purchase decision. However, in the decision-making literature, it is recognised that decision makers are flexible and construct decision-making processes as they adapt and respond to decision tasks (Bettman et al., 1998; Payne et al., 1988). Adaptive decision-making changes the structure of the decision problem so that each decision maker devises different processes. Individuals therefore create more complex process flows and follow different pathways through the model. Process instances often show divergences from the main route as consumers skip, add and reorder the process steps (Langley, 1999; Dorn et al., 2010). The actual process path is entirely selected at run-time. Although consumers use the stages of the traditional model, the stages do not actually represent clearly defined steps of the process because of iterations between stages. Consumers constantly move between stages, which leads to spaghetti shaped processes that, prima facie, do not have a clear structure and appear chaotic (Karimi et al., 2014). In summary, the stage model does not accurately represent the complexity of the actual decision-making processes of consumers because the stages concept is too simplistic and does not represent variations in the process flow. It is therefore important to find better ways of modelling and analysing purchase decisions. This research uses elements of the stage model and applies modelling techniques from the Information Systems literature to uncover a structure behind the complex and iterative decision-making processes. 


\subsection{Impact of consumer characteristics on decision-making process flow}

Differences in individual consumer characteristics mean that purchase decisionmaking processes are not deterministic (Volkner \& Werners, 2002) but are highly related to the characteristics of the decision-maker (Chowdhury et al., 2009; Ranaweera et al., 2005; Simonson \& Nowlis, 2000). Consumers exhibit different patterns in their decision making based on their characteristics (Bhatnagar \& Ghose, 2004). Prior research indicates that purchase processes are influenced by consumers’ decision-making style and knowledge of product (Karimi et al., 2015). These individual characteristics define the motivation and capabilities of consumers (Heitmann et al., 2007) and can therefore explain differences in decision behaviour. For example, maximizers and those with low level of knowledge perform more cycles in their decision-making processes, compared to satisficers and those with high level of knowledge (Karimi et al. 2015). However, differences in the patterns and flows of these cycles are not known. Understanding how online consumers construct the purchase decision-making process is crucial to marketers as consumer can choose to exit the purchase path at any given time (Srinivasan et al., 2016). This research examines the purchase decision-making process for each archetype from a behavioural perspective.

Decision-making style is a "macro-motivational construct" which affects the purchase decision process (Chowdhury et al., 2009). Individuals differ in their decision-making style (maximizers and satisficers) and the amount of effort and resources they allocate to a decision process. They therefore follow different decision-making paths (Schwartz et al., 2002). Maximizers have a tendency to find the best possible option and are motivated to perform intensive information search and evaluation before making a choice. Satisficers, in contrast, aim to choose a good enough option. They allocate less effort to the decision process and consider fewer alternatives. 
In an online purchase context, maximizers and satisficers need to constantly make decisions on their decision pathway. Being motivated with different objectives in their decision behaviour, they adopt different decision-making strategies and consequently follow varied processes. Satisficers shape their decision-making strategy around simplification and reduced effort whereas maximizers attempt to ensure an optimum choice of alternative options. It is therefore expected that maximizers will display more complex and iterative processes than satisficers, particularly in the information search and evaluation stages.

The impact of consumer knowledge on the decision-making process has been widely demonstrated (Bughin et al., 2010; Karimi et al., 2015; Rickwood \& White, 2009). A consumer's knowledge affects the starting point and also the way that processes unfold (Kaas, 1982) by dictating an individual’s decision-making capacity (Alba \& Hutchinson, 1987; Heitmann et al., 2007). Consumers with high level of knowledge can be more selective in accessing information (Brucks, 1985; Cowley \& Mitchell, 2003) and evaluate the information with less effort (Alba \& Hutchinson, 1987; Cowley \& Mitchell, 2003), which simplifies the decision-making process (Heitmann et al., 2007). They start the process by collecting brand information and a set of situational attributes, because they are already aware of product attributes and possible alternatives (Sproule \& Archer, 2000). They are able to reflect on their previous experience, easily identify the important attributes and choice criteria (Heitmann et al., 2007), distinguish between relevant from irrelevant information and quickly start to compare alternatives against the criteria (Brucks, 1985).

Those consumers with a low level of knowledge are not as capable at retrieving information about alternatives and choice criteria from memory. They require more cognitive effort for decision-making (Heitmann et al., 2007) and construct different decision-making process patterns (Bettman \& Park, 1980). They start the process by developing an overall understanding (concept-formation) of product attributes and creating a potential consideration 
set (Sproule \& Archer, 2000; Kaas, 1982). We therefore expect consumers with a low level of knowledge to have more complex processes because they will perform additional steps to achieve their “concept-formation”. However, there is no empirical evidence illustrating the actual online purchase decision-making processes that each consumer archetype follows.

\subsection{Impact of consumer characteristics on decision-related outcomes}

Understanding purchase behaviour and designing successful platforms that support consumer decisions require a better understanding of decision-making process outcomes (Kamis et al., 2008). The outcome of a purchase process can be measured by consumer satisfaction (Gu et al., 2013; McKinney \& Yoon, 2002). As consumers travel through the purchase journey, the nature of the satisfaction they experience changes (Oliver, 2014). Consumer satisfaction after the purchase reflects on the product consumption, and has received significant attention in prior research. However, consumer satisfaction in relation to the decision-making behaviour that involves the experience of searching, evaluating and selecting an alternative has been largely neglected and requires further research (Huber \& Seiser, 2001). In line with previous research (e.g. Iyengar \& Lepper, 2000; Valenzuela et al., 2009), we have examined two decision related outcomes: satisfaction with the choice and satisfaction with the process.

\subsubsection{Satisfaction with the choice and decision-making process}

Consumer satisfaction, its antecedents and consequents are well documented in current research. Satisfaction is defined as a function of consumer expectations and the extent to which these expectations are met (LaBarbera \& Mazursky, 1983; Oliver, 1980). It is a consequence of the experiences during all steps of the purchase process (McKinney \& Yoon, 
2002). However, only a limited number of studies have examined satisfaction in relation to the purchase process (e.g. Kohli et al., 2004).

Satisfaction with the process and satisfaction with the choice are conceptually different and vary in their underlying dimensions and antecedents (Fitzsimons, 2000; Gu et al., 2013). Additionally, they have diverse consequences on consumer behaviour and affect retailers in different ways (Fitzsimons et al., 1997). Studies of satisfaction have mainly focused on satisfaction with the choice as the outcome of the decision-making process (Oliver, 1980; Gu et al., 2013) and have overlooked the importance of satisfaction with the decision-making process itself. Satisfaction with the decision-making process, which examines experiences in arriving at purchase decisions (Westbrook et al., 1978), is an equally important decision related outcome (Fitzsimons, 2000; Fitzsimons et al., 1997; Iyengar \& Lepper, 2000; Zhang \& Fitzsimons, 1999).

As different archetypes of consumers follow different decision-making processes, we expect their experience of the decision-related outputs to be diverse. Heitmann, Lehmann, and Herrmann (2007) indicated that evaluation effort invested in a purchase decision affects satisfaction with the choice and process differently. Increased effort enhances satisfaction with the choice while it has a negative impact on satisfaction with the process. Consumer characteristics such as decision-making style and knowledge of product determine the evaluation effort allocated to a decision-making process by affecting certain process-related mechanisms, such as time allocated to the process and number of alternatives examined (Karimi et al., 2015). This research aims to provide a deeper understanding of how such mechanisms, triggered by individual characteristics, affect satisfaction with the choice and also the decision process. 


\subsubsection{Impact of individual characteristics on satisfaction with the choice}

Decision-making style of consumers, as a macro-motivational construct, affects their purchase decision process (Chowdhury et al., 2009) and feeling of satisfaction (e.g. Iyengar et al., 2006; Schwartz et al., 2002). Maximizers who aim to find the best alternative are motivated to perform intensive information search and evaluate many alternatives before making a choice (Schwartz et al., 2002). Evaluation of more options might affect their satisfaction with the choice (Desmeules, 2002; Iyengar \& Lepper, 2000). Some studies have suggested that maximizers, due to the large number of alternatives they examine, experience feelings of regret and tend to be less satisfied. These studies have measured the overall decision makers’ affective state (i.e. Polman, 2010), life satisfaction and regret (e.g. Iyengar et al., 2006; Schwartz et al., 2002). By measuring inconsistent concepts of satisfaction that relate to different aspects of consumer experience, contradictory findings are reported. Additionally, these studies are conducted in experimental conditions where the number of alternatives were manipulated (e.g. Iyengar \& Lepper, 2000) or very particular measures of alternative generation were applied (e.g. Polman, 2010). It is important to examine the impact of decision-making style on satisfaction in an actual choice behaviour (Schwartz et al., 2002) but there is limited understanding of maximizers' and satisficers' levels of satisfaction with the choice and process in real-life decision scenarios.

In an online purchase context where many alternatives are available, maximizers search for and evaluate more options compared to satisficers (Karimi et al., 2015). Results on the impact of number of alternatives on consumer satisfaction with the choice are inconsistent (Scheibehenne et al., 2010). One argument is that more options may pose problems for maximizers who cannot examine all available alternatives and may therefore doubt their choice (Schwartz et al., 2002). An opposing viewpoint is that in an online environment there 
are many opportunities for seeking and identifying alternatives, which could help maximizers achieve a higher degree of optimization compared to offline experiences. In fact, maximizing behaviour can lead to both better and worst outcomes compared to satisficing behaviour (Polman, 2010). In line with Chowdhury, Ratneshwar and Mohanty (2009), we suggest that satisficers perform superficial search processes and their simplified decision-making processes do not support them in reaching a decision point. In contrast, maximizers are motivated to find the best option and perform intensive processes, retrieve more information and compare many alternatives. As they invest more effort in their purchase decision-making, they tend to reach a point where they are confident in their choices. Their ability to justify their decision increases their choice confidence and satisfaction with the selected option (Heitmann et al., 2007). Justification is one of the challenges of choice tasks for decision makers (Xia \& Sudharshan, 2002). A superficial purchase process that is highly dependent on simplification strategies will therefore make it difficult for consumers to justify their choice because they only evaluate a small fraction of alternatives available. A larger number of alternatives creates a better sense of overall product quality distribution, leads to moreinformed choices, and enhances confidence in the choice (Scheibehenne et al., 2010). This follows Heitmann, Lehmann, and Herrmann (2007) findings, which suggest a positive relationship between evaluation effort and satisfaction with the choice. We therefore expect maximizers to be more satisfied than satisficers with their choices in an online shopping environment where many options are available. The higher number of alternatives that maximizers examine mediates this relationship:

H1a: Decision-making style (maximizers/ satisficers) affects consumer satisfaction with the choice. Maximizers are more likely to be satisfied with their choices compared to satisficers. 
H1b: The relation between decision-making style and satisfaction with choice is mediated by the number of alternatives evaluated in the process. Maximizers evaluate more options, which enhances their satisfaction with the choice.

\subsubsection{Impact of individual characteristics on satisfaction with the process}

While satisfaction with the choice is driven by confidence in choice, satisfaction with the decision-making process is influenced by negative emotions such as stress and frustration that are caused by the complexity of a decision process and difficulty of arriving at a choice (Heitmann et al., 2007). In this situation, consumers experience feeling of anxiety and fear of not making a right decision (Broniarczyk \& Griffin, 2014), hence their evaluation of the decision outcome is affected (Fitzsimons, 2000; Valenzuela et al., 2009). However, not all consumers experience such emotions in a similar manner.

Consumers who anticipate experiencing post-decision regret may evaluate the alternatives more thoroughly and allocate more time and effort to the decision-making process to minimize the potential occurrence of negative emotions (Zeelenberg, 1999). Therefore, maximizers who are more likely to experience feeling of regret (Iyengar et al., 2006), allocate more effort and time to the decision process compared to satisficers (Karimi et al., 2015), which leads to more complex processes. Consumers with low level of knowledge are not able to simplify the decision-making process and cannot maintain their focus on relevant information. This increases the complexity of their decision making (Broniarczyk \& Griffin 2014; Huffman \& Kahn, 1998). In addition to their inability to perform effective processes, those with a lower level of knowledge experience more cognitive limitations and negative emotions such as frustration. Decision processes under negative emotion become more extensive (Luce et al., 1997). Therefore, a low level of knowledge leads to allocation of more effort to the decision (Heitmann et al., 2007). 
Consumers with a higher level of knowledge perform a more focused evaluation strategy (Brucks, 1985; Cowley \& Mitchell, 2003) and assess the information with less effort (Cowley \& Mitchell, 2003).

Maximizers and consumers with low levels of knowledge perform more complex processes compared to satisficers and consumers with high levels of knowledge (Karimi et al, 2015), and allocate more time to their decision-making. More time spent on a complex process decreases the level of satisfaction with the decision process (Iyengar et al., 2006). In summary, maximizers and those with low levels of knowledge allocate more time to the decision-making process to cope with negative emotions, which leads to decreased satisfaction with the decision-making process.

H2a: Decision-making style influences satisfaction with the process. Satisficers are more likely to be satisfied with the decision-making process compared to maximizers.

H2b: The relation between decision-making style and satisfaction with the process is mediated by the duration of the process. Satisficers allocate less time to the process which enhances their satisfaction with the process.

H3a: Consumers' knowledge of the product influences their satisfaction with the process. Those with a high level of knowledge are more likely to be satisfied with the decision-making process compared to those with a low level of knowledge.

H3b: The relation between knowledge of product and satisfaction with the process is mediated by the duration of the process. Those with a high level of knowledge allocate less time to the process which enhances their satisfaction with the process. 


\section{Research Design}

\subsection{Study one: purchase process flow}

Capturing the nuances and complexity of online purchase decision-making processes is a difficult problem. A methodology is proposed that captures behavioural aspects of dynamic processes as they occur, identifies behavioural units of interest and models the relation and flow of those units, identifies groups of related actions, and provides a visual presentation of process flow, which can indicate patterns and variations within and between consumer archetypes.

Observing consumers directly enables the identification of different behavioural patterns (Ranaweera et al., 2005). To capture the level of detail required for modelling behavioural processes, video recording of the actual consumer buying process was found to be the most suitable method. A log of user interactions with the website disregards the context of decisions and ignores those parts of the process that take place in the minds of decision makers, which are crucial in understanding the process progression and outcomes. Reporting of a decision process after the event, despite simplifying the data collection and allowing for a larger sample, is problematic because recalled behaviour is different from the actual behaviour (Ericsson \& Simon, 1980). In addition, recalled behaviour is affected by the final outcome, which could create bias. Using a methodology that trace the process directly is therefore more appropriate (Jacoby et al., 1978). Laboratory experiments (Holschke, 2010; Reijers \& Mendling, 2008) and video recordings (Byrne at al., 1999) have been employed in studies of detailed process modelling and were found to be very effective.

\subsubsection{Procedure}

Fifty-five participants whose ages ranged from 23 to 52 were recruited for the study. The sample was comprised of 35 postgraduate students enrolled in $\mathrm{PhD}$ or MBA programmes 
and 20 individuals working in academia and industry. There were 33 males and 22 females in the sample. Criteria-based purposeful sampling was used to ensure that participants were able to complete the decision task. Inclusion criteria required participants to have competent Internet skills and previous experience of online shopping. Participants were given an online purchase decision-making scenario and their entire set of activities was recorded using video. They were randomly assigned to one of two purchase scenarios: (1) selecting a bank account; (2) buying a mobile phone package. These two high-involvement products were chosen because they required participants to perform engaging decision-making processes and active information search behaviour. This would facilitate modelling of process flows and help identify behavioural differences between archetypes.

A video camera was located next to the participants, which captured the computer monitor and a microphone recorded their voice. Participants were instructed to use the think aloud technique (Benbunan-Fich, 2001; Dhar \& Sherman, 1996; Johnson, 1984) in order for the verbal protocols to be generated. Verbal protocols, which are common practice in consumer research (see for example Payne, 1976), are crucial for capturing the part of the process that occurs in the mind of consumers. The task was designed in a way that consumers were not given any direction and were free to visit any website and collect any information in order to capture the most realistic process instance. They were asked to stop when they reached a decision on their preferred product. At the end of the session, all participants were interviewed about their behaviour at different steps of the process to verify the accuracy of recorded processes.

In total, 19 hours and 7 minutes of video recording was gathered. Video recording and verbal protocols generate a large amount of data that result in an extensive coding procedure involving many instances of desired behaviours. This method resulted in the coding of 3,083 activities and 1,874 transitions between stages. It should be noted that the sample size of this 
study is considerably larger than previous similar studies that utilized video recordings of eleven hours (Johnson, 1984), eight hours (Byrne et al., 1999) and eight hours (BenbunanFich, 2001) to capture user behaviour.

Questionnaires were used to measure participants’ level of knowledge and decisionmaking style. Measurements used in this research are validated and widely used in other studies. Decision-making style was measured with 13 items introduced by Schwartz et al. (2002) and two items were adopted from Brucks (1985) to measure knowledge of the product. Participants were grouped based on their level of product knowledge (High/Low) and decision-making style (Maximizer/Satisficer). In order to allocate participants to each group, a single composite score of maximization tendency and knowledge were used. For decision-making style, the median split (4.46) differentiated between maximizers and satisficers. This classification approach is consistent with earlier research that has used the decision-making style scale (Iyengar et al., 2006; Karimi et al., 2015; Schwartz et al., 2002). To determine the level of knowledge (Low/ High) the centre of the scale was used as a cutoff point (Grewal et al., 1998).

\subsubsection{Process modelling and analysis of process flows for different individuals}

The entire decision-making process was captured by video recording techniques and a think aloud method (Benbunan-Fich, 2001; Johnson, 1984). Modelling the process in a meaningful manner is only possible through the choice of the right modelling method. Activity diagrams that show the behavioural view of a process (Chang et al., 2000) were therefore selected. Using this approach, the process is disaggregated based on behavioural

roles and activities. Activities are the actions performed by the decision maker. Behavioural roles are broadly defined as modules of behaviour that contain activities undertaken by the decision maker (Papamichail \& Robertson, 2005). In this study, behavioural roles are 
observable modules of behaviour that are common to most purchase process models. They were adopted from an online purchase decision-making model (Karimi et al., 2014), which includes stages of traditional purchase process model (Engel et al., 1968; Howard \& Jagdish, 1969) and stages of decision-making processes (Holtzman, 1989); namely, need recognition, formulation, search, evaluation, appraisal and choice. Deconstructing a purchase process to these modules of behaviour allow us to analyse the flow of the process in a systematic and meaningful way.

This coding process has three steps. The activities of participants were captured and identified (step one) using cues such as an action or a dialogue (see Table 1). They are then assigned to a behavioural role (step two). For example, when a participant is searching for an alternative, this activity is assigned to the search role, whereas, when they are comparing two alternatives, this activity is assigned to an evaluation role. As the process unfolds and activities are coded, the relations between roles are constructed, which indicates the flow of the process. The higher-order structure of phases is then defined by groupings of multiple activities across several behavioural roles that are all supporting the same higher-level purpose or objective (step three). The phases are defined by using the verbal expression of the participants combined with the context of their online decision-making process, giving a meaningful structure to the sequence of activities. The purpose of the consumer at a given point in time can only be understood through the analysis of participants' own explanations. The identification of phases is therefore made possible by the think-aloud method. Each process model was analyzed together with the verbal protocol in order to define the sets of related activities within a phase and the critical points where the transition between phases occurs.

Insert Table 1 around here 
Our analysis revealed that above the sequence of behavioural roles there is a higherlevel, linear structure to the decision-making process. That is, a set of behavioural roles can be grouped into phases, where a phase serves a higher-level, common purpose. Five distinct phases of the decision-making process were clearly identified: Context setting; Initial exploration; Cognitive exploration; Review and refinement; and Final choice (see Figure 2). All participants clearly (verbally) indicated a change in their purpose as they moved between phases. The phases are defined in Figure 2. The roles within each phase have the same purpose, which is different to the aim of a role in a traditional buying model. For example, context setting captures the set of roles that support the decision-maker's first objective of understanding the context of the problem, in particular to identify possible alternatives. The context setting phase involves the start of the process followed by two behavioural roles: (1) an initial formulation of the problem that is supported by (2) a search for possible alternatives, which results in a re-formulation of the problem. Figure 3 shows the expansion of the phase 'cognitive exploration' of the decision space into its constituent behavioural roles, where each role is defined in turn by a more detailed set of individual activities.

Insert Figure 2 around here

Insert Figure 3 around here

In summary, using this modelling approach, we map all the activities conducted by participants at a detailed level onto each behavioural role, breaking down the process into a sequence of steps. Then based on participants' descriptions of the process flows, we identify a higher-order structure that illustrates the rationale behind this sequence, which we term phases. Phases are able to depict the patterns of the decision-making process as they go beyond a sequence of actions and represent the overall objectives of the decision maker. 
The reliability of the coding was tested by comparing the results of two independent coders for a sample of $20 \%$ of all processes. This is higher than the suggested $10 \%$ of the total sample (Hodson, 1999). The two coders reached an agreement of 91\%. This relatively high percentage is due to the clear cues and coding scheme in this particular research. Any differences between coders were resolved through discussions.

Incorporating phases of online purchase decision-making process, instances of individual process models were then transformed to a process flow model using an adaptation of Mintzberg's (1976) path configuration method. The path configuration method has the advantage of identifying the patterns and the flow of the process. By combining the activity diagrams and path configuration it is possible to identify process patterns and capture differences between individuals. An example of a typical path configuration model for each archetype is presented in the following section. This method has also been adapted by Boonstra (2003) to show that decisions fall into different categories based on different factors.

\subsection{Study 2: Consumer characteristics, purchase process and decision-related outcomes}

To test the hypotheses, an experiment was designed and 82 participants were recruited to perform an online purchase decision-making task, of whom 45 were male and 37 were female. The sample was composed of 44 postgraduate students and 38 professionals working in academia and industry. We captured nearly 33 hours of decision-making processes.

Similar scenarios to study one were used. Participants were randomly assigned to one of the two scenarios. Questionnaires were used to measure participants’ level of knowledge, decision-making style, satisfaction with the choice and satisfaction with the process. Decision-making style and knowledge of the product were measured as in study one. Although satisfaction has often been measured with a single-item scale, we opted for multi- 
item measures of satisfaction because they tend to be more reliable (Yi, 1990). Satisfaction with the choice and satisfaction with the process were each measured by 6 items from Fitzsimons (2000) and Fitzsimons et al. (1997). Cronbach's alpha for satisfaction with the choice and process was .85 and .82, respectively. Inclusion in the sample required competent Internet skills and prior experience of online shopping. The number of alternatives considered by each participant and the duration of the process were captured and recorded by the authors.

\section{Results}

\subsection{Study one: Impact of consumer archetypes on online purchase process flow}

Regardless of consumer decision-making archetypes, all users followed a phase model, which is a detailed representation of online behaviour in practice. Our methodology enabled us to observe this higher-level behavioural pattern, where there is a linear transition from one phase to another, i.e. the nature of the transitions between phases is a sequential linear process. However, within the individual phases, there were highly iterative patterns between behavioural roles. The methodology allowed us to capture these complex iterations between behavioural roles and also identify the sets of iterative journey patterns that constitute individual behavioural phases. The iterations between behavioural roles, and the transitions between phases, were observed and measured by the coding cues. The coding cues were grouped into actions such as opening a webpage or navigating through a website, and dialogues, which expressed the motivation of the actions, e.g. feelings and needs, an explanation of the search process or mental models of the evaluation process. In general, the transition between phases was inferred from the participants' dialogues that expressed their motivational cues. These results, which capture a combination of linear and iterative search 
patterns, may partly explain the differences between decision process models in the literature that range from highly linear (e.g. Engel et al., 1968; Howard \& Jagdish, 1969) to more iterative models (e.g. Papamichail and Robertson, 2005). It also makes an empirical contribution by presenting a holistic representation of consumer decision making behaviour in practice.

Insert Table 2 around here

The four consumer archetypes, introduced by Karimi et al. (2015), are shown in Table 2. Analysis of process instances conducted for this work revealed that there are similar patterns of behaviour for members within each archetype and distinct variations between archetypes. Figure 4 shows a representative process model for each archetype. As the figure illustrates, maximizers perform more complex processes and allocate more effort to the decision-making process, compared to satisficers. Their cognitive exploration phase includes multiple iterations between search, evaluation and formulation stages, highlighting their motivation to find the best alternative. Although consumers with low level of knowledge construct a complex process and allocate additional effort to the decision-making process, the nature of this complexity is different from maximizers. These consumers perform two additional phases (context setting and initial exploration) to identify relevant attributes and create a consideration set. Whereas those with high level of product knowledge reflect on their previous experience and retrieve this information from memory, thereby skipping these two phases. These new results extend the work by Karimi et al. (2015) by providing evidence of how consumer characteristics affect the flow of purchase decision-making process. The descriptive analysis of the results for each archetype is given in Table 3. 
Insert Figure 4 around here

Insert Table 3 around here

\subsubsection{General Differences between Maximizers and Satisficers}

Maximizers conduct many more iterations between behavioural roles than satisficers and this provides evidence for their need to reach an optimal decision, i.e. they continue to formulate, search, evaluate and appraise additional information until they have reached what they consider to be the best possible decision. In contrast to the in-depth analysis of information by maximizers, satisficers tend to conduct more perfunctory reading and evaluation of information. The dominant evaluation strategy for maximizers is attribute-based evaluation, which involves the comparison of all alternatives for each attribute in turn (Bettman \& Zins, 1979). In contrast, satisficers perform an alternative-based strategy that involves evaluating options one by one against all criteria before moving on to evaluating the next alternative (Bettman \& Zins, 1979; Dhar, 1996). This supports the relation between alternative-based evaluation and satisficing decision strategy (Dhar, 1996; Lindberg et al., 1989). Maximizers carry out a thorough review and refinement step by checking whether the process has been comprehensive and all suitable alternatives are assessed. Satisficers skip through the review and refinement process quickly to finalise their choice.

\subsubsection{General Differences between High and Low Levels of Knowledge}

The first two phases, Context setting and Initial exploration, are only performed by consumers with a low knowledge level. These two phases are performed in order to form their initial understanding of the decision problem. This result is in line with previous literature (Kaas, 1982; Sproule \& Archer, 2000) that suggests consumer knowledge underlies 
the execution of concept formation. Our results provide empirical evidence for such behaviour. Consumers with a high level of product knowledge develop choice criteria that remain the same throughout the decision-making process whereas those with low level of product knowledge change their criteria as the decision-making process unfolds.

\subsubsection{Specific Differences Between Individual Archetypes}

The tendency to change choice criteria for consumers with a low level of product knowledge is higher for maximizers than satisficers, i.e. the choice criteria for Archetype 3 (Maximizer / Low Knowledge) change frequently, for Archetype 1 (Satisficer / Low Knowledge) they change slightly, and for Archetypes 2 (Satisficer / High Knowledge) and 4 (Maximizer / High Knowledge), criteria remain the same. In the Context setting phase, satisficers with low product knowledge rely on external search (i.e. search using external sources) whereas maximizers with low product knowledge conduct more internal search supported by external search. A possible explanation is that satisficers find it less mentally taxing to conduct external search than think deeply about the problem by evaluating internal information. In the early steps of decision-making, cognitively easy strategies are commonly used (Payne et al., 1988). In particular, an individual who has less motivation to process information will exert less cognitive effort and allocate less mental energy to the task (Verplanken, 1993). Satisficers therefore might expend less cognitive effort by avoiding internal information search compared with maximizers.

Each archetype has a unique combination of range of information sources and review depth : Archetype 1 (Satisficer / Low Knowledge) reviews a wide range of information sources in a superficial manner; Archetype 2 (Satisficer / High Knowledge) reviews a narrow range of information sources in a superficial manner; Archetype 3 (Maximizer / Low Knowledge) reviews a wide range of information sources in an in-depth manner; Archetype 4 (Maximizer / High Knowledge) reviews a narrow range of information sources in an in-depth 
manner. In general, maximizers always use in-depth analysis of information and satisficers always conduct superficial reviews of information, and low product knowledge results in a wide range of information sources being used, whereas high product knowledge is accompanied by a narrow range of information sources.

Maximizers start off with a large set of possible alternatives. However, there is an important difference that is dependent on product knowledge level. Those with a low product knowledge retain a high number of alternatives until the end of the cognitive exploration phase whereas those with high product knowledge are more confident and decisive in rejecting alternatives earlier on in the decision-making process and therefore only have a small set of alternatives when they approach the end of their evaluation.

\subsection{Study two: Impact of consumer archetypes on the decision-related outcomes}

Study two examines whether individual characteristics, through their impact on the way the decision-making process is constructed, influence decision-related outcomes. To test hypotheses H1a, H2a and H3a, multivariate analysis of variance (MANOVA) was conducted with decision-making style (maximizer/satisficer) and knowledge of product (low/high) as the independent variables and satisfaction with the choice and satisfaction with the process as dependent measures. We controlled for the potential impact of product. The results are shown in Table 4.

Insert Table 4 around here

The MANOVA results reveal a significant main effect for decision-making style on satisfaction with choice $(\mathrm{F}=8.34, \mathrm{p}<.05)$. Therefore, $\mathrm{H} 1 \mathrm{a}$ is supported. We report that in the context of an online purchase decision, maximizers are in fact more satisfied with their choices compared to satisficers. In line with Chowdhury, Ratneshwar and Mohanty (2009), 
we found in study one experiments that satisficers perform superficial search processes. Findings suggest that their simplified decision-making processes do not support them in reaching a decision point. In contrast, maximizers perform intensive processes and compare many alternatives. As they invest more effort in evaluating alternatives, they tend to reach a point where they are confident in their choice.

The result for the impact of decision-making style on satisfaction with the process is insignificant; H2a is not supported. This might be due to the fact that maximizers' expectations of the purchase process are different from that of satisficers. Even though they perform more complex processes, as a result of their innate decision-making style, they are accustomed to such complexity. Satisfaction is a function of consumer expectations and the extent to which these expectations are met. Therefore, added complexity does not affect their level of satisfaction with the process as they already expect a purchase decision to be more challenging and complex.

The effect of knowledge of product on satisfaction with the process was significant $(\mathrm{F}=16.50, \mathrm{p}<.005)$. Therefore, H3a is supported. Consumers with a high level of knowledge are more satisfied with the purchase decision process because they are able to perform a more structured process. No interaction effect between the independent variables was found, suggesting a consistent effect of the above relationships. Additionally, no correlation between satisfaction with the choice and satisfaction with the process was observed.

To test H1b, H2b and H3b, we assessed the mediating role of two decision process characteristics (i.e. duration and number of alternatives) in the relations between consumer characteristics and satisfaction with the choice and process. Steps proposed by Baron and Kenny (1986) were followed. Product has been used as a covariate in all analyses. There is no correlation between decision-making style and knowledge of product, or satisfaction with the choice and satisfaction with the process. 
Decision-making style has a significant effect on satisfaction with the choice ( $b=-1.4$, $p<.005)$ and number of alternatives $(b=-2.8, p<.005)$. Number of alternatives significantly influences satisfaction with choice $(b=.33, p<.005)$. The effect of decision-making style on satisfaction with the choice is not significant when the mediator, number of alternatives, is included $(b=-.45, p=.37)$. Figure 5 (a) shows a significant indirect effect of decision making style on satisfaction with the choice through the number of alternatives. The number of alternatives fully mediates this relationship. A Sobel test of the mediation further confirms the significant impact of the mediator (Sobel test $=-.94, p<.005$ ). Therefore, maximizers evaluate a larger number of alternatives compared with satisficers, which results in higher level of satisfaction with their choice. H1b is supported. Decision-making style does not have a significant effect on satisfaction with the process, so H2b is not supported.

The effect of product knowledge on satisfaction with the process $(b=-1.6, p<.005)$ and duration $(b=4.87, p=<05)$ is significant. Duration has a significant influence on satisfaction with the process $(b=-.10, p<.005)$. The effect of knowledge on satisfaction with the process is reduced when duration is included as a mediator $(b=-1.14, p<.05)$, but remains significant. This suggests a partial mediation (Figure 5(b)). As the confidence interval for the indirect effect (95\% CI [ -.94, -.15]) does not include zero, there is clear evidence of partial mediation (Preacher \& Hayes, 2004). The results of the Sobel test also support the meditating role of duration (Sobel test $=-.50, \mathrm{P}<.05$ ). Therefore, H3b is supported. Consumers with a high level of knowledge are able to evaluate the information in a shorter period of time, which enhances their level of satisfaction with the process.

Insert Figure 5 around here 


\section{Discussions and implications}

\subsection{Theoretical and methodological Implications}

This research facilitates our understanding of online consumer purchase decisionmaking processes for different consumer archetypes. The results indicate that both decision making style and knowledge of product lead to variations in the way purchase decisionmaking behaviour is shaped and perceived by consumers.

Using a rigorous methodology adapted from the managerial decision making (Mintzberg et al., 1976) and business process modelling (Holt, 2009) literatures, the first study shows that online purchase decision-making processes do not map neatly to the linear stages of the traditional consumer decision process models. The captured processes of Figure 4 provide clear evidence for the constructive nature of purchase processes (Bettman et al., 1998) and their dependence on characteristics of the decision-maker (Chowdhury et al., 2009; Ranaweera et al., 2005) in online platforms. By introducing the phase model, we have demonstrated an underlying structure for these seemingly chaotic and complex processes (Karimi et al., 2014) which has important theoretical and managerial implications. We identified five higher-level phases of the decision-making process: Context setting; Initial exploration; Cognitive exploration; Review and refinement; and Final choice. The phase model contributes to the current consumer decision-making literature as it offers a much more realistic picture of consumer practice. Additionally, it captures the inherent complexity of decision-making behaviour, which is evident by the high number of dynamic iterations between stages of traditional models. The phase model is much more effective at describing and analysing the characteristics of decision-making process flow at a very detailed and granular level, whilst still providing an abstract model that identifies distinctive inter-linked phases. 
In addition, this approach provides a clear understanding of variations in decision behaviour. The phase model offers a valuable analytical tool that can clearly indicate interesting differences in the online behaviour of different consumer groups. Our results clearly identify, in a visual manner, differences in the decision-making behaviour of four consumer archetypes. The impact of consumer demographics on patterns of online behaviour has been previously reported (e.g. Bhatnagar \& Ghose, 2004). More recently, Karimi et al (2015) have shown that consumers' decision-making style and knowledge of product explain variations in the quantifiable characteristics of the purchase decision-making process, e.g. number of cycles, duration of the process, number of alternatives and criteria. By capturing the phase models of the entire online decision-making process, this study provides further insights and illustrates that consumer decision-making style and knowledge of product also determine the way that phases are constructed.

The diagrammatic differences identified in the first study capture the mechanics underlying the behaviour of each archetype and illustrate the qualitative differences between them. We show that both maximizers and those with low level of knowledge perform more intensive processes, but the nature of this intensity varies. In fact, these two individual characteristics affect the purchase process in different ways. Maximizers perform more complex processes with a larger number of iterations within phases, compared to satisficers. This is in line with findings of Chowdhury et al. (2009) that illustrate maximizers' tendency to engage in more extensive search behaviour. Additionally, those with a low level of knowledge engage in a complex process by performing additional phases. Due to their lower capacity of decision-making and limited knowledge of available alternatives and choice criteria, they need to invest more effort in initial phases (Sproule \& Archer, 2000). This supports previous studies that have found a significant relationship between product knowledge and effort invested in a purchase decision (Beatty \& Smith,1987). 
The results of the second study highlight the impact of decision-making style and knowledge of product on decision-related outcomes, satisfaction with the choice and decision-making process. These two individual characteristics affect the evaluation effort allocated to a decision-making process such as time spent and number of alternatives examined (Karimi et al., 2015) and therefore influence consumer satisfaction. Our findings are consistent with that of Heitmann et al. (2007); we confirm that the effort invested in a purchase decision affects satisfaction with the choice and process differently. We found that decision making style influences satisfaction with the choice through number of alternatives and product knowledge explains satisfaction with the decision-making process by affecting the duration of the process. In addition, this provides further evidence for conceptual differences that exist between the two types of satisfaction by showing that their antecedents are different, as previously suggested (see Fitzsimons, 2000; Gu et al., 2013).

Maximizers are more satisfied than satisficers with their choice. This suggests that the evaluation of a large number of alternatives increases the confidence in choice for maximizers, while the superficial process followed by satisficers impedes them from reaching a satisfactory decision and one in which they are confident. Our results for the effect of decision-making style appear to contradict some prior findings (e.g. Iyengar et al., 2006; Schwartz et al., 2002; Broniarczyk \& Griffin, 2014). As suggested by Schwartz et al. (2002), we stress the importance of studying the relation between decision-making style and satisfaction in an actual choice behaviour. Furthermore, we posit that having high product knowledge gives consumers a better way of structuring the decision-making process, thereby making the whole process more effective and faster which increases satisfaction with the process. It is already known that those with high level of knowledge assess the information with less effort (Cowley \& Mitchell, 2003; Heitmann et al., 2007). We have shown that less 
effort for high knowledge consumers, manifested in shorter duration of decision making process, enhances their satisfaction with the process.

In terms of methodological contribution, this paper demonstrates how the use of a process modelling technique can capture complex purchase decision-making processes, identify behavioural patterns, and reveal variations between consumer archetypes. It shows that activity diagrams, previously used to model dynamic behaviour of e-commerce processes (Chang et al., 2000), can be applied to dynamic purchase processes. A structured approach has been devised to illustrate the flow of decision-making processes by combining video recording and activity diagrams and by adapting Mintzberg's path configuration method.

\subsection{Managerial implications}

This research has several important managerial implications, particularly for online retailers who aim to enhance the online consumer journey. The archetype approach can be used to segment online customers in order to customize and facilitate their decision-making processes according to their individual needs. An improvement in the online process has the potential to encourage completion and improve conversion rates of searchers to buyers (Soonsawad, 2013). It can also increase the level of satisfaction, which is likely to improve customer retention (Gustafsson et al., 2005). Our results suggest that consumers with a low level of knowledge and those with satisficing tendency require more assistance in their online purchase decision making activities compared to those with a high level of knowledge and maximizing tendency.

Marketers need to enhance satisfaction with the purchase process for those consumers with low level of knowledge. In order to perform a decision task, low knowledge consumers spend more time completing additional phases (i.e. context setting and initial exploration) which leads to decreased satisfaction with the process. Online platforms should be designed 
to help consumers with low level of knowledge identify the main criteria and main alternatives early on in the process. For example, providing a clear indication of important criteria and using comparison tools to assist in the identification of relevant alternatives can reduce the time allocated to additional phases and improve satisfaction with the process.

Marketers should also encourage satisficers to perform a more extensive evaluation of alternatives. Satisficers allocate less effort to the decision-making process and evaluate fewer alternatives with the motivation to simplify the decision task. However, they tend to be less satisfied with their choices because evaluating fewer alternatives does not help them reach a decision point. Although current online practices are shaped around simplification of purchase processes, our results suggest that online platforms should encourage satisficers to engage with the process and consider a larger number of alternatives, possibly through automated tools that reduce cognitive effort, which is appealing to this group.

As segmentation and targeting practices are becoming more complex and focused on behavioural differences, these research findings can be applied in a broader context. Marketers can use the proposed consumer archetypes in purchase decisions within the store environment or for customization of marketing messages targeted at specific archetypes.

\subsection{Limitations and Future Research}

In an experiment design, participant behaviour might be influenced by the environment and in this case awareness of the video recorder. Several measures were taken to minimize such effects. Participants were told that the camera only records their monitor, that there is no desired behaviour, and that they are free to approach their decision as they would in a real purchase scenario. For the purpose of this research video recording of processes as they occur was necessary and the benefits of this method outweighed its limitations. In order to capture the decision-making process, two complex high-involvement products were 
selected which are associated with similar behaviour. Both products pose complex decision problems to consumers, which are typical of many online buying processes. It is therefore important for managers to understand the decision-making behaviour for these types of problem. However, the choice of two sectors might present limitations to the generalization of the findings to other market contexts and future research should apply the concepts to different product categories.

This research proposes four archetypes of consumers based on their decision-making style and knowledge of product that influence purchase decision making processes and outcomes. Further research can apply this segmentation to other contexts in order to investigate variations in consumer decision-making behaviour. Behavioural differences in consumer search and evaluation strategies were observed among archetypes such as evaluation strategy and type of information sources. Future studies can focus on the significance of such differences using alternative research methods that allow a larger sample. Based on our findings, a number of practical implications are suggested for ecommerce in general. Future research could explore how online purchase processes could be improved to take into account the characteristics of the phase model, in particular the overall purpose of each phase. We also call for further in-depth consumer behaviour studies of online buying behaviour using a synthesis of video data, web logs and systematic modelling tools. 


\section{References}

Alba, J. W., \& Hutchinson, J. W. (1987). Dimensions of consumer expertise. Journal of Consumer Research, 13(4), 411-454.

Bhatnagar, A., \& Ghose, S. (2004). Online information search termination patterns across product categories and consumer demographics. Journal of Retailing, 80(3), 221-228.

Baron, R. M., \& Kenny, D. A. (1986). The moderator-mediator variable distinction in social psychological research: Conceptual, strategic, and statistical considerations. Journal of personality and social psychology, 51(6), 1173.

Beatty, S. E., \& Smith, S. M. (1987). External search effort: An investigation across several product categories. Journal of consumer research, 14(1), 83-95.

Benbunan-Fich, R. (2001). Using protocol analysis to evaluate the usability of a commercial web site. Information \& Management, 39(2), 151-163.

Bettman, J. R., Luce, M. F., \& Payne, J. W. (1998). Constructive consumer choice processes. Journal of Consumer Research, 25(3), 187-217.

Bettman, J. R., \& Park, C. W. (1980). Effects of prior knowledge and experience and phase of the choice process on consumer decision processes: A protocol analysis. Journal of consumer research, 7(3), 234-248.

Bettman, J. R., \& Zins, M. A. (1979). Information format and choice task effects in decision making. Journal of Consumer Research, 6(2), 141-153.

Boonstra, A. (2003). Structure and analysis of IS decision-making processes. European Journal of Information Systems, 12(3), 195-209.

Brengman, M., Geuens, M., Weijters, B., Smith, S. M., \& Swinyard, W. R. (2005). Segmenting Internet shoppers based on their Web-usage-related lifestyle: a crosscultural validation. Journal of Business Research, 58(1), 79-88.

Broniarczyk, S. M., \& Griffin, J. G. (2014). Decision difficulty in the age of consumer 
empowerment. Journal of Consumer Psychology, 24(4), 608-625.

Brucks, M. (1985). The effects of product class knowledge on information search behavior. Journal of Consumer Research, 12(1), 1.

Bughin, J., Doogan, J., \& Vetvik, O. J. (2010). A new way to measure word-of-mouth marketing. McKinsey Quarterly, 3(2), 113-116.

Byrne, M. D., John, B. E., Wehrle, N. S., \& Crow, D. C. (1999). The tangled Web we wove: a taskonomy of WWW use. In Proceedings of the SIGCHI conference on Human Factors in Computing Systems (pp. 544-551). ACM.

Chang, Y. L., Chen, S., Chen, C. C., \& Chen, I. (2000). Workflow process definition and their applications in e-commerce. In Multimedia Software Engineering, 2000. Proceedings. International Symposium on (pp. 193-200). IEEE.

Chowdhury, T. G., Ratneshwar, S., \& Mohanty, P. (2009). The time-harried shopper: Exploring the differences between maximizers and satisficers. Marketing Letters, 20(2), 155-167.

Cowley, E., \& Mitchell, A. A. (2003). The moderating effect of product knowledge on the learning and organization of product information. Journal of Consumer Research, 30(3), 443-454.

Darley, W. K., Blankson, C., \& Luethge, D. J. (2010). Toward an integrated framework for online consumer behavior and decision making process: A review. Psychology and Marketing, 27(2), 94-116.

Desmeules, R. (2002). The impact of variety on consumer happiness: Marketing and the tyranny of freedom. Academy of Marketing Science Review, 12, 1-18.

Dhar, R. (1996). The effect of decision strategy on deciding to defer choice. Journal of Behavioral Decision Making, 9(4), 265-281.

Dhar, R., \& Sherman, S. J. (1996). The effect of common and unique features in consumer 
choice. Journal of Consumer Research, 23(3), 193-203.

Dorn, C., Burkhart, T., Werth, D., \& Dustdar, S. (2010). Self-adjusting recommendations for people-driven ad-hoc processes. In International Conference on Business Process Management (pp. 327-342). Springer, Berlin, Heidelberg.

Engel, J. F., Kollat, D. T., \& Blackwell, R. (1968). Consumer Behavior, New York: Holt, Rinehart and Winston.

Ericsson, K. A., \& Simon, H. A. (1980). Verbal reports as data. Psychological review, 87(3), 215.

Fitzsimons, G. J. (2000). Consumer response to stockouts. Journal of Consumer Research, 27(2), 249-266.

Fitzsimons, G. J., Greenleaf, E. A., \& Lehmann, D. R. (1997). Decision and consumption satisfaction: Implications for channel relations. Marketing Studies Center Working Paper Series (313).

Frambach, R. T., Roest, H. C. A., \& Krishnan, T. V. (2007). The impact of consumer Internet experience on channel preference and usage intentions across the different stages of the buying process. Journal of Interactive Marketing, 21(2), 26-41.

Grewal, D., Krishnan, R., Baker, J., \& Borin, N. (1998). The effect of store name, brand name and price discounts on consumers' evaluations and purchase intentions. Journal of retailing, 74(3), 331-352.

Gu, Y., Botti, S., \& Faro, D. (2013). Turning the page: The impact of choice closure on satisfaction. Journal of Consumer Research, 40(2), 268-283.

Gustafsson, A., Johnson, M. D., \& Roos, I. (2005). The effects of customer satisfaction, relationship commitment dimensions, and triggers on customer retention. Journal of marketing, 69(4), 210-218.

Hall, A., Hall, A., Towers, N., \& Towers, N. (2017). Understanding how Millennial shoppers 
decide what to buy: digitally connected unseen journeys. International Journal of Retail \& Distribution Management, 45(5), 498-517.

Heitmann, M., Lehmann, D. R., \& Herrmann, A. (2007). Choice goal attainment and decision and consumption satisfaction. Journal of marketing research, 44(2), 234-250.

Hodson, R. (1999). Analyzing documentary accounts (No. 128). Sage.

Hölscher, C., \& Strube, G. (2000). Web search behavior of Internet experts and newbies. Computer networks, 33(1-6), 337-346.

Holschke, O. (2010). Impact of granularity on adjustment behavior in adaptive reuse of business process models. In International Conference on Business Process Management (pp. 112-127). Springer, Berlin, Heidelberg.

Holt, J. (2009). A pragmatic guide to business process modelling. BCS, The Chartered Institute.

Holtzman, S. (1989). Intelligent Decision Systems, Addison-Wesley, Reading, MA.

Howard, J. A. S., \& Jagdish, N. (1969). The theory of buyer behavior.

Huber, O., \& Seiser, G. (2001). Accounting and convincing: The effect of two types of justification on the decision process. Journal of Behavioral Decision Making, 14(1), 69.

Huffman, C., \& Kahn, B. E. (1998). Variety for sale: mass customization or mass confusion? Journal of retailing, 74(4), 491-513.

Iyengar, S. S., \& Lepper, M. R. (2000). When choice is demotivating: Can one desire too much of a good thing? Journal of personality and social psychology, 79(6), 995.

Iyengar, S. S., Wells, R. E., \& Schwartz, B. (2006). Doing better but feeling worse. Psychological Science, 17(2), 143.

Jacoby, J., Chestnut, R. W., \& Fisher, W. A. (1978). A behavioral process approach to information acquisition in nondurable purchasing. Journal of marketing research, 
15(4) 532-544.

Johnson, M. D. (1984). Consumer choice strategies for comparing noncomparable alternatives. Journal of Consumer Research, 11(3), 741-753.

Kaas, K. P. (1982). Consumer habit forming, information acquisition, and buying behavior. Journal of Business Research, 10(1), 3-15.

Kamis, A., Koufaris, M., \& Stern, T. (2008). Using an attribute-based decision support system for user-customized products online: an experimental investigation. MIS Quarterly, 32(1), 159-177.

Karimi, S., Papamichail, K. N., \& Holland, C. P. (2014). Purchase Decision Processes in the Internet Age Decision Support Systems III-Impact of Decision Support Systems for Global Environments (pp. 57-66): Springer.

Karimi, S., Papamichail, K. N., \& Holland, C. P. (2015). The effect of prior knowledge and decision-making style on the online purchase decision-making process: A typology of consumer shopping behaviour. Decision Support Systems, 77, 137-147.

Kohli, R., Devaraj, S., \& Mahmood, M. A. (2004). Understanding determinants of online consumer satisfaction: A decision process perspective. Journal of Management Information Systems, 21(1), 115-136.

LaBarbera, P. A., \& Mazursky, D. (1983). A longitudinal assessment of consumer satisfaction/dissatisfaction: the dynamic aspect of the cognitive process. Journal of marketing research, 20(4) 393-404.

Langley, A. (1999). Strategies for theorizing from process data. The Academy of Management Review, 24(4), 691-710.

Lindberg, E., Gärling, T., \& Montgomery, H. (1989). Differential predictability of preferences and choices. Journal of Behavioral Decision Making, 2(4), 205-219.

Luce, M. F., Bettman, J. R., \& Payne, J. W. (1997). Choice processing in emotionally 
difficult decisions. Journal of Experimental Psychology: Learning, Memory, and Cognition, 23(2), 384.

McKinney, V., \& Yoon, K. (2002). The measurement of web-customer satisfaction: An expectation and disconfirmation approach. Information systems research, 13(3), 296315.

Mintzberg, H., Raisinghani, D., \& Theoret, A. (1976). The structure of" unstructured" decision processes. Administrative science quarterly, 21(2), 246-275.

Morrison, M. A., Cheong, H. J., \& McMillan, S. J. (2013). Posting, Lurking, and Networking: Behaviors and Characteristics of Consumers in the Context of UserGenerated Content. Journal of Interactive Advertising, 13(2), 97-108.

Oliver, R. L. (1980). A cognitive model of the antecedents and consequences of satisfaction decisions. Journal of marketing research, 17(4), 460-469.

Oliver, R. L. (2014). Satisfaction: A behavioral perspective on the consumer. Routledge.

Papamichail, K.N., \& Robertson, I. (2005). Integrating Decision Making and Regulation in the Management Control Process, Omega, 33(4), 319-332.

Payne, J. W. (1976). Task complexity and contingent processing in decision making: An information search and protocol analysis. Organizational behavior and human performance, $16(2)$, 366-387.

Payne, J. W., Bettman, J. R., \& Johnson, E. J. (1988). Adaptive strategy selection in decision making. Journal of Experimental Psychology: Learning, Memory, and Cognition, 14(3), 534.

Payne, J., Bettman, J. R., \& Johnson, E. J. (1991). Consumer decision making. Handbook of consumer behaviour, 50-84.

Payne, J. W., Bettman, J. R., \& Johnson, E. J. (1993). The adaptive decision maker. Cambridge University Press. 
Polman, E. (2010). Why are maximizers less happy than satisficers? Because they maximize positive and negative outcomes. Journal of Behavioral Decision Making, 23(2), 179190.

Preacher, K. J., \& Hayes, A. F. (2004). SPSS and SAS procedures for estimating indirect effects in simple mediation models. Behavior research methods, 36(4), 717-731.

Ranaweera, C., McDougall, G., \& Bansal, H. (2005). A model of online customer behavior during the initial transaction: Moderating effects of customer characteristics. Marketing Theory, 5(1), 51.

Reijers, H., \& Mendling, J. (2008). Modularity in process models: Review and effects. Business Process Management (pp. 20-35): Springer.

Rickwood, C., \& White, L. (2009). Pre-purchase decision-making for a complex service: retirement planning. Journal of Services Marketing, 23(3), 145-153.

Scheibehenne, B., Greifeneder, R., \& Todd, P. M. (2010). Can there ever be too many options? A meta-analytic review of choice overload. Journal of Consumer Research, 37(3), 409-425.

Schwartz, B., Ward, A., Monterosso, J., Lyubomirsky, S., White, K., \& Lehman, D. R. (2002). Maximizing versus satisficing: Happiness is a matter of choice. Journal of Personality and Social Psychology, 83(5), 1178-1197.

Simonson, I., \& Nowlis, S. M. (2000). The role of explanations and need for uniqueness in consumer decision making: Unconventional choices based on reasons. Journal of Consumer Research, 27(1), 49-68.

Smith, A. D., \& Rupp, W. T. (2003). Strategic online customer decision making: leveraging the transformational power of the Internet. Online information review, 27(6), 418-432.

Sproule, S., \& Archer, N. (2000). A buyer behavior framework for the development and design of software agents in e-commerce. Internet Research: Electronic Networking 
Applications and Policy, 10(5), 396-405.

Soonsawad, P. (2013). Developing a new model for conversion rate optimization: A case study. International Journal of Business and Management, 8(10), 41.

Srinivasan, S., Rutz, O. J., \& Pauwels, K. (2016). Paths to and off purchase: quantifying the impact of traditional marketing and online consumer activity. Journal of the Academy of Marketing Science, 44(4), 440-453.

Valenzuela, A., Dhar, R., \& Zettelmeyer, F. (2009). Contingent response to selfcustomization procedures: Implications for decision satisfaction and choice. Journal of marketing research, 46(6), 754-763.

Verplanken, B. (1993). Need for cognition and external information search: Responses to time pressure during decision-making. Journal of Research in Personality, 27(3), 238-252.

Volkner, P., \& Werners, B. (2002). A simulation-based decision support system for business process planning. Fuzzy Sets and Systems, 125(3), 275-287.

Westbrook, R. A., Newman, J. W., \& Taylor, J. R. (1978). Satisfaction/dissatisfaction in the purchase decision process. Journal of Marketing, 42(4), 54-60.

Xia, L., \& Sudharshan, D. (2002). Effects of interruptions on consumer online decision processes. Journal of Consumer Psychology, 12(3), 265-280.

Yi, Y. (1990). A critical review of consumer satisfaction. Review of marketing, 4(1), 68-123.

Zeelenberg, M. (1999). Anticipated regret, expected feedback and behavioral decision making. Journal of behavioral decision making, 12(2), 93.

Zhang, S., \& Fitzsimons, G. J. (1999). Choice-process satisfaction: The influence of attribute alignability and option limitation. Organizational behavior and human decision processes, 77(3), 192-214. 


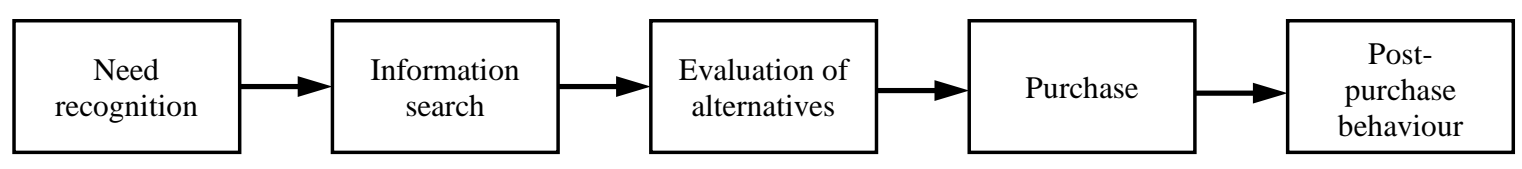

Figure 1: Stages of online purchase decision-making process

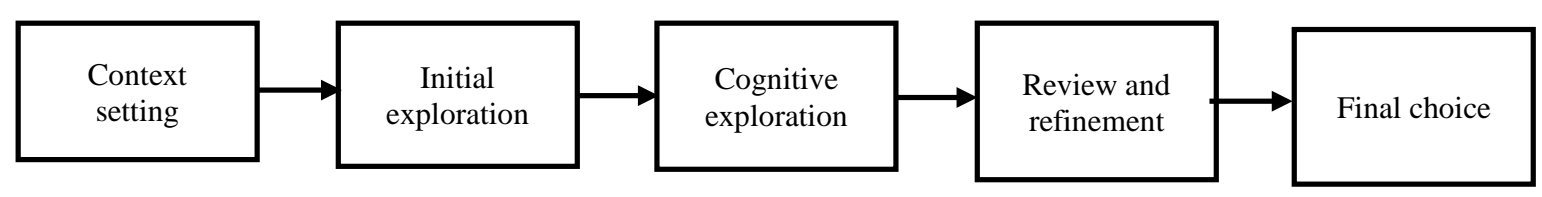

Figure 2: The five data-driven phases of an online purchase process

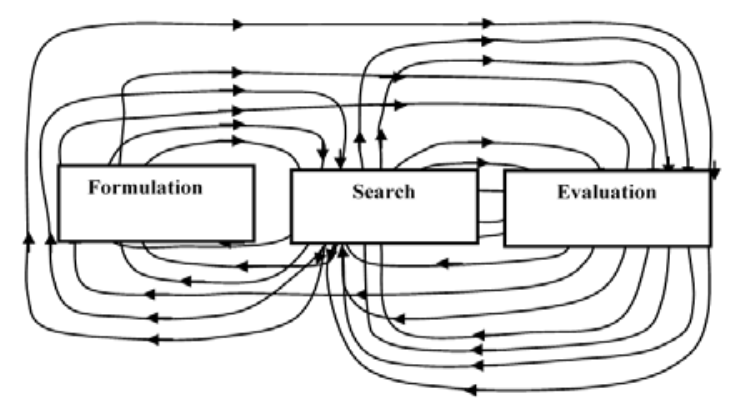

Figure 3: An example of multiple behavioural roles involved in one decision-making phase 


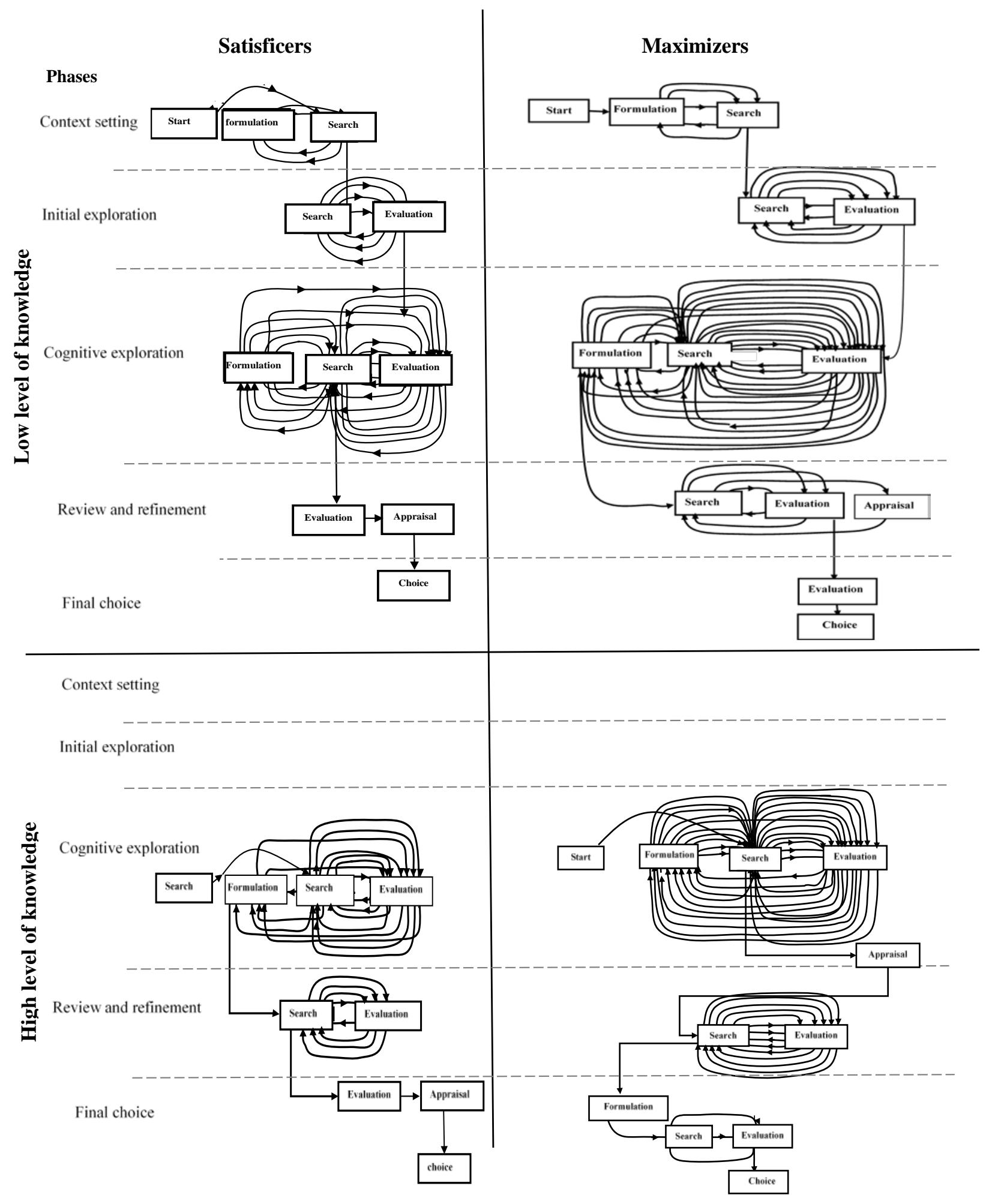

Figure 4: Decision Making Process Flow Models for Different Consumer Archetypes 


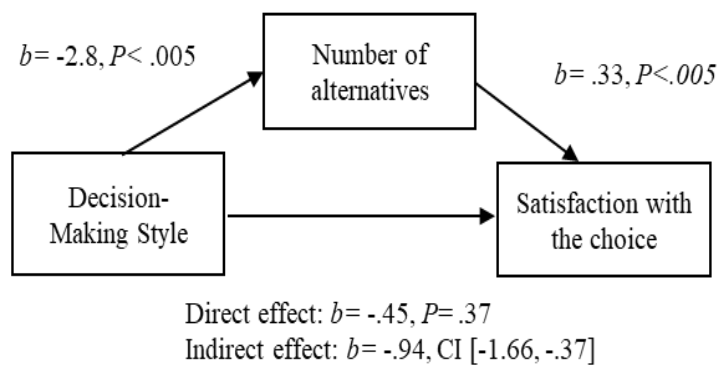

Control variable: Sector

(a)

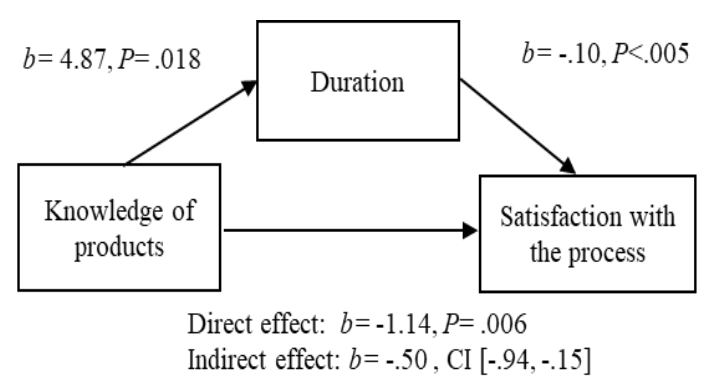

Indirect effect: $b=-.50, \mathrm{CI}[-.94,-.15]$

Figure 5: Mediation results 
Table1: Types of cues used in coding the video data

\begin{tabular}{|c|l|}
\hline Types of Cue & \multicolumn{1}{c|}{ Cues used for coding } \\
\hline \multirow{3}{*}{ Actions } & Opening a webpage \\
& Typing \\
& Navigating \\
& Scanning \\
& Reading \\
\hline \multirow{3}{*}{ Dialogues } & Explaining the process plan \\
& Explaining the current, previous or next action, Expressing feelings \\
& and needs \\
& Explaining mental evaluation or changes in criteria or alternatives \\
\hline
\end{tabular}

Table 2: Archetypes of online consumers

\begin{tabular}{|c|c|c|}
\hline & \multicolumn{2}{|c|}{ Knowledge of product } \\
\hline $\begin{array}{c}\text { Decision-making } \\
\text { style }\end{array}$ & Low & High \\
\hline Satisficer & Satisficer with low level of knowledge & Satisficer with high level of knowledge \\
\hline Maximizer & $\begin{array}{c}\text { Maximizer with low level of } \\
\text { knowledge }\end{array}$ & Maximizer with high level of knowledge \\
\hline
\end{tabular}


Table 3: Behavioural patterns of archetypes.

\begin{tabular}{|c|c|c|}
\hline \multirow[b]{2}{*}{$\begin{array}{c}\text { Knowledge } \\
\text { of Product }\end{array}$} & \multicolumn{2}{|r|}{ Decision-Making Style } \\
\hline & Satisficers & Maximizers \\
\hline Low & $\begin{array}{l}\text { Archetype 1: Satisficer / Low } \\
\text { Process: Includes all phases. Relatively little iteration. } \\
\text { Context setting: Scan the environment to identify alternative options, } \\
\text { neglect decision criteria. } \\
\text { Initial exploration: A small number of options evaluated against a small } \\
\text { number of criteria using external information. } \\
\text { Cognitive exploration of the decision space: Criteria may change slightly. } \\
\text { Alternatives gradually generated and slowly eliminated. A superficial } \\
\text { review of a large number of information sources. Alternative-based } \\
\text { evaluation. } \\
\text { Review and refinement: A scant evaluation and appraisal of alternatives. } \\
\text { Decision-related outcomes: Low level of satisfaction with both the } \\
\text { process and the choice. }\end{array}$ & $\begin{array}{l}\text { Archetype 3: Maximizer / Low } \\
\text { Process: Includes all phases. Complex and highly iterative. } \\
\text { Context setting: A small number of options are generated. Clear initial decision criteria are } \\
\text { defined. } \\
\text { Initial exploration: Options are evaluated against the initial criteria. Preliminary evaluation } \\
\text { relies on internal information supported by external search. } \\
\text { Cognitive exploration of the decision space: The criteria change frequently, the alternatives } \\
\text { change constantly and the search space remains relatively large till the end of the process. A } \\
\text { wide range of information sources is accessed with in-depth reading of material. Attribute- } \\
\text { based evaluation. } \\
\text { Review and refinement: A thorough and clear evaluation and appraisal of the decision making, } \\
\text { with additional search and evaluation conducted as necessary until they are confident that the } \\
\text { choice is optimal. } \\
\text { Decision-related outcomes: Low level of satisfaction with the process and high level of } \\
\text { satisfaction with the choice. }\end{array}$ \\
\hline High & $\begin{array}{l}\text { Archetype 2: Satisficer / High } \\
\text { Process: Omits context setting and initial exploration phases. Relatively } \\
\text { little iteration. } \\
\text { Cognitive exploration of the decision space: Evaluation criteria remain } \\
\text { the same throughout this phase. A small set of alternatives are considered } \\
\text { and quickly evaluated without the addition of new options. A superficial } \\
\text { review of a small number of information sources. Alternative-based } \\
\text { evaluation. } \\
\text { Review and refinement: A scant evaluation and appraisal of the } \\
\text { alternatives. } \\
\text { Decision-related outcomes: High level of satisfaction with the process } \\
\text { and low level of satisfaction with the choice. }\end{array}$ & $\begin{array}{l}\text { Archetype 4: Maximizer / High } \\
\text { Process: Omits the Context setting and Initial exploration. Complex and highly iterative. } \\
\text { Cognitive exploration of the decision space: The choice criteria are clearly defined and remain } \\
\text { the same throughout the process. A large set of alternatives is generated at the beginning and } \\
\text { options are reduced with decisive rejections of unsuitable ones, resulting in a small } \\
\text { consideration set relatively quickly. A limited range of information sources is used in depth. } \\
\text { Attribute-based evaluation. } \\
\text { Review and refinement: A thorough and clear evaluation and appraisal of the decision-making } \\
\text { process, with additional search and evaluation performed until the choice has been checked } \\
\text { against the small final set of alternatives. } \\
\text { Decision-related outcomes: } \\
\text { High level of satisfaction with the process and high level of satisfaction with the choice. }\end{array}$ \\
\hline
\end{tabular}


Table 4: MANOVA results

\begin{tabular}{|c|c|c|c|c|c|c|}
\hline & \multicolumn{3}{|c|}{ Decision-making style } & \multicolumn{3}{c|}{ Knowledge of product } \\
\hline Dependent variables & $F$ & $\begin{array}{c}p- \\
\text { value }\end{array}$ & $\begin{array}{c}\text { Mean } \\
\text { Square }\end{array}$ & $F$ & $\begin{array}{c}p- \\
\text { value }\end{array}$ & $\begin{array}{c}\text { Mean } \\
\text { Square }\end{array}$ \\
\hline Satisfaction with the process & 5.92 & .07 & 21.35 & $16.50 * *$ & .000 & 59.48 \\
\hline Satisfaction with the choice & $8.34 *$ & .005 & 33.79 & 1.219 & .27 & 4.94 \\
\hline
\end{tabular}

$* p<.05 \quad * * p<.005$ 